\title{
Citologia anal como método de rastreamento para a deteç̧ão precoce do câncer anal: esfregaços com algodão hidrófilo são mesmo insatisfatórios? ${ }^{1}$
}

\author{
Anal cytology as a screening method for early detection of anal cancer: are hydrophilic \\ cotton smears really unsatisfactory?
}

\author{
Ivan Tramujas da Costa e Silva², Felicidad Santos Gimenez ${ }^{3}$, Ricardo Alexandre Gonçalves \\ Guimarães $^{4}$, Romildo Torres Camelo ${ }^{5}$, Manoel Nilzomar Damasceno Melo ${ }^{6}$, Flávio Silveira de \\ Barros $^{7}$, Adriana Daumas ${ }^{2}$, Celso Rômulo Barbosa Cabral ${ }^{8}$, Erica Liberato Guimarães ${ }^{9}$
}
1. Trabalho decorrente de Projeto de Bolsa de Iniciação Científica realizado na Universidade Federal do Amazonas (UFAM) e no Hospital de Aeronáutica de Manaus em 2002-3 sob o título "Citologia anal como método de massa de detecção precoce de lesões escamosas intraepiteliais do canal anal”.
2. Prof. Aux. do Departamento de Clínica Cirúrgica da UFAM.
3. Cirurgiã Geral do Hospital Universitário Getúlio Vargas da UFAM.
4. Patologista do Hospital Universitário Getúlio Vargas da UFAM.
5. Patologista da Fundação Centro de Controle de Oncologia.
6. Prof. Adj do Departamento de Patologia da UFAM.
7. Infectologista do Instituto de Medicina Tropical do Amazonas.
8. Prof. Adj do Departamento de Estatística da UFAM.
9. Acadêmica do $5^{\circ}$ ano do Curso de Medicina da UFAM.

\section{RESUMO}

Objetivo: Testar se swabs de algodão hidrófilo são capazes de produzir esfregaços de secreção anal que permitam leituras citológicas satisfatórias ao Pap-a em comparação a métodos tradicionais de coleta. Métodos: 318 pacientes sofreram coleta de material anal para a realização do Pap-a. 180 deles realizaram a captura de células anais com material sorteado (escova citológica, swab de poliéster ou cotonete de algodão). Foram comparados entre si os materiais usados para a coleta de secreção anal segundo a capacidade de produção de leitura citológica satisfatória. Resultados: Não houve diferença estatística entre o algodão hidrófilo, o poliéster e a escova na capacidade de produzir leituras citológicas satisfatórias ( $p>0,05)$. Conclusão: No material estudado, o algodão hidrófilo foi tão bom quanto o poliéster ou a escova citológica na produção de leituras citológicas adequadas no Pap-a.

Descritores: Neoplasias do ânus. Papillomavirus. Citologia.

\section{ABSTRACT}

Purpose: To test the ability of analpaps performed with cotton swab smears to produce satisfactory cytologic readings as compared to traditional sampling materials. Methods: 318 consecutive patients were examined at the Ambulatório Araújo Lima of Hospital Universitário Getúlio Vargas in the Anal Cancer Prevention Week and were sampled for the performance of analpap. 180 of these patients were randomly sorted to be sampled by either one of the following materials: cytologic brush, dacron swab or cotton swab. The ability of cotton in producing satisfactory anal cytologic readings as compared to dacron and cytologic brush was analised. Results: There was no statistical difference among the materials employed in the ability to produce satisfactory citological readings in analpaps. ( $>0.05$ ) Conclusion: Our results showed that cotton swabs were as efficient 
as dacron swabs or cytologic brushes in the ability to produce satisfactory analpap readings.

Key words: Anus neoplasms. Papillomavirus. Cytology.

\section{Introdução}

O câncer anal é uma afecção reconhecidamente rara na população geral, ${ }^{1}$ que passou a ser objeto de maior preocupação quando começaram a surgir relatos de incidência e prevalência aumentadas em determinados centros. ${ }^{2,3}$ Tal alteração epidemiológica passou a ser observada em determinados grupos populacionais, definidos como de risco para o desenvolvimento da afecção, ${ }^{1}$ a saber: indivíduos de ambos os sexos praticantes do sexo anal receptivo, ${ }^{2,4}$ indivíduos sexualmente promíscuos, ${ }^{5}$ portadores de DST - tais como infecções causadas pelo HPV, ${ }^{3,6} \mathrm{a}$ sífilis, ${ }^{7}$ o estado de portador do $\mathrm{HIV},{ }^{8}$ a gonorréia, a infecção pelo vírus do Herpes simples tipo II e a infecção pela Chlamydia trachomatis ${ }^{2}$-, portadores de lesões anais crônicas benignas que cursam com inflamação (hemorróidas, fístulas, fissuras anais), ${ }^{2,4}$ indivíduos transplantados, ${ }^{1,8}$ usuários de drogas injetáveis, ${ }^{8}$ tabagistas ${ }^{6}$ e, ainda, indivíduos que têm o câncer anal por influência de fatores genéticos. ${ }^{4}$

Com o escrutínio metódico destinado à afecção em vários centros, observou-se que o tipo de carcinoma mais comumente encontrado no canal anal e ânus era o epidermóide, ${ }^{9}$ exatamente o mesmo tipo histológico que mais incide no colo do útero. ${ }^{3}$

O câncer cervical, há muito conhecido e extensamente estudado, está intimamente ligado à infecção causada pelo HPV, principalmente assestada no epitélio de transição escamocolunar do canal cervical, sendo considerado uma doença adquirida, fruto da transmissão do vírus pelo contato sexual. Esta neoplasia teve sua incidência diminuída com a adoção do exame sistemático de esfregaços citológicos obtidos pela coleta de secreções do colo do útero pela técnica de coloração de Papanicolaou cervical, Pap-c. ${ }^{10}$

A presença do DNA do papiloma vírus humano, especialmente dos sorotipos 16, 18, 31, 33 e 35, ${ }^{7,9}$ também foi observada na maioria dos casos de carcinoma epidermóide anal, sinalizando que seu padrão biológico seria idêntico ao do câncer cervical. ${ }^{11}$ Da mesma forma que no colo do útero, o HPV, no canal anal, apresenta predileção pela zona de transição anal (ZTA) escamocelular, ${ }^{12}$ parecendo lógico então que esfregaços celulares feitos de material coletado da região pudessem auxiliar na detecção precoce de lesões citopáticas provocadas pelo HPV, o que acabou dando origem ao que se convencionou chamar de Papanicolaou anal (Papa). ${ }^{13}$

Estudando grupos de indivíduos sob maiores chances de desenvolver o câncer anal, vários núcleos de pesquisa começaram a obter resultados parciais que apontaram para a possibilidade de se poder conseguir a mesma redução dos índices epidemiológicos da doença, a exemplo do que se tem podido obter com o câncer do colo uterino. ${ }^{14}$

O Pap-a começou a ser realizado coletando-se o material anal com swabs de poliéster (dacron), que alegadamente seriam superiores ao algodão hidrófilo por liberarem para a lâmina de leitura microscópica mais facilmente as células captadas. ${ }^{15}$

O uso da escova citológica, apesar de eventualmente poder conferir melhores resultados de leituras citológicas, ${ }^{16}$ tem representado um papel secundário em relação ao Pap-a.

Da mesma forma, apesar de oferecer leituras citológicas mais purificadas, livres de debris celulares e restos fecais, a citologia obtida do acondicionamento do material de coleta em meio líquido (Thin Prep) é mais dispendiosa do que a realizada com esfregaços de poliéster em lâminas fixados em álcool etílico a $95 \% .^{17}$

Dentre todos os materiais de coleta que podem ser utilizados no canal anal, muito provavelmente o swab ou o cotonete de algodão hidrófilo é o mais barato. Resta realmente conferir, como é alegado, ${ }^{15}$ se os resultados das leituras citológicas que produz são inferiores aos produzidos pelos materiais mais tradicionalmente empregados - dacron ou escova citológica.

O presente trabalho pretendeu então explorar um assunto cada vez mais abordado na literatura médica internacional, e inserir no acervo nacional os primeiros passos da experiência amazonense com o estudo do Pap-a como método de diagnóstico precoce de lesões anais pré-malignas. Uma preocupação com custos, facilidade de reprodução e confiabilidade do método de coleta de material anal para a realização 
do Pap-a foram os interesses deste estudo, cujo objetivo primordial foi o de avaliar a habilidade de esfregaços de secreção anal produzidos com cotonetes de algodão hidrófilo em produzir resultados de leitura citológica satisfatórios pelo método de Papanicolaou, em comparação com esfregaços produzidos com swabs de poliéster ou com escovas citológicas.

\section{Métodos}

O presente trabalho baseou-se nos dados obtidos de pacientes que atenderam à chamada para participar da Semana de Prevenção do Câncer Anal, desenvolvida de 24 a 28/2/2003, no Ambulatório Araújo Lima (AAL) do Hospital Universitário Getúlio Vargas. A SPCA foi amplamente veiculada na imprensa falada e escrita de Manaus e pela distribuição de folhetos explicativos em locais estratégicos da cidade, com o intuito de convocar para a campanha de prevenção indivíduos pertencentes aos seguintes grupos de risco para o desenvolvimento do câncer anal: pessoas com feridas anais crônicas (fissuras, fístulas, abscessos); tabagistas; pessoas imunodeprimidas (HIV positivas, transplantadas); portadores de história de infecções sexualmente transmissíveis (HPV, gonorréia, etc.); e pessoas de ambos os sexos que praticam o sexo anal .

Setecentos e noventa pacientes consecutivos de ambos os sexos responderam à chamada e compareceram ao AAL para atendimento e foram entrevistados e submetidos à coleta de material anal para esfregaço citológico até 31/5/2003.

Por ocasião da entrevista para a coleta de material anal, e após preenchimento de Termo de Consentimento Informado, um protocolo de estudo foi preenchido, cujos dados permitiram a identificação do tipo de paciente a ser estudado como pertencente a grupo controle ou a grupo de risco para o desenvolvimento do câncer anal.

Material anal foi coletado de cada paciente por meio da introdução de cotonete de algodão, umedecido em água, 3 centímetros para o interior do orifício anal. Uma vez nesta posição, o cotonete foi rodado $360^{\circ}$ circunferencialmente em torno de seu eixo, sendo a seguir retirado do canal em um movimento em espiral. Um esfregaço do material aderido ao cotonete foi imediatamente realizado sobre uma lâmina seca, sendo o cotonete rolado sobre a superfície transparente da lâmina em várias faixas horizontais coalescentes e sobrepostas, de forma a preencher a lâmina com o produto do esfregaço. A lâmina foi, na seqüência, rapidamente acondicionada em um recipiente cilíndrico plástico de transporte, preenchido com álcool etílico a 95\% como solução fixadora. Cada recipiente foi hermeticamente fechado, adequadamente identificado e enviado para estudo citológico no Laboratório de Citopatologia do Departamento de Patologia da Universidade Federal do Amazonas.

No Laboratório, cada lâmina foi corada pelo método de Papanicolaou, ${ }^{18}$ sendo, a seguir, examinada sob microscopia ótica pelo citopatologista.

Para cada paciente, apenas um esfregaço foi produzido e lido, de forma que cada leitura de Papa seria respectiva a um único paciente estudado.

A análise citológica dos esfregaços procurou por células do epitélio do baixo reto (colunar), zona de transformação (escamocolunar) e anoderma (escamoso). Os achados foram rotulados de normal, anormal (ASCUS - células escamosas atípicas de significado indeterminado; LSIL - lesão intraepitelial escamosa de baixo grau; ou HSIL - lesão intraepitelial escamosa de alto grau), ou insatisfatório, à semelhança do que é preconizado pelo Sistema de Bethesda para o Pap-c. ${ }^{19}$ Foram considerados satisfatórios os achados rotulados de normais e anormais.

Para avaliar a eficácia do algodão hidrófilo como material de coleta para a produção de esfregaços anais, trezentos pacientes, dos 790 estudados, foram sorteados para a realização do esfregaço ora com cotonete de algodão, ora com swab de poliéster, ora com escova citológica. A capacidade de cada material de coleta em produzir esfregaços satisfatórios (com resultados normal ou anormal) ou insatisfatórios foi analisada. Os resultados insatisfatórios obtidos assim foram definidos por apresentarem paucicelularidade, defeitos na execução do esfregaço, ou por excesso de matéria fecal nos mesmos.

Os achados citológicos, indistintamente considerados em relação ao material de coleta, foram tabulados comparando, de acordo com cada sexo, o obtido em pacientes pertencentes a grupos de risco para o desenvolvimento do câncer anal com o observado em pacientes controle, ou seja, que não apresentaram na história ou no exame físico nenhum fator de risco para o desenvolvimento do câncer anal.

Para análise dos resultados foi aplicado o teste 
do qui-quadrado para tabelas de contingências. ${ }^{20}$

\section{Resultados}

Foram obtidos, dos 790 pacientes estudados, trezentos e dezoito resultados de citologia anal (Papa), passando então a ser esta amostra de 318 pacientes a aqui considerada para análise.

A Tabela 1 demonstra a distribuição da amostra populacional estudada em relação ao sexo dentro de cada um dos dois grupos de estudo analisados (Risco e Controle), denotando não haver diferença estatística entre sexos quanto à característica de pertencer ou não a grupo de risco $(\mathrm{p}>0,05)$.

TABELA 1 - Distribuição dos grupos de estudo quanto ao sexo

\begin{tabular}{lcc}
\hline \multirow{2}{*}{ Sexo } & \multicolumn{2}{c}{ Grupo } \\
\cline { 2 - 3 } Feminino & Risco & Controle \\
Masculino & $119(71,3 \%)$ & $48(28,7 \%)$ \\
\hline
\end{tabular}

$\mathrm{p}=0,643$

TABELA 2 - Distribuição dos resultados do Pap-a segundo a natureza do material de coleta e capacidade de produzir resultados satisfatórios em pacientes sorteados

\begin{tabular}{lcc}
\hline & \multicolumn{2}{c}{ Resultado Satisfatório } \\
\cline { 2 - 3 } Material & Sim & Não \\
\hline Algodão & $31(72,1 \%)$ & $12(27,9 \%)$ \\
Escova & $62(80,5 \%)$ & $15(19,5 \%)$ \\
Poliéster & $49(81,7 \%)$ & $11(18,3 \%)$ \\
\hline
\end{tabular}

$\mathrm{p}=0,478$

Dos 318 pacientes estudados por terem tido seus resultados citológicos emitidos, cento e oitenta tiveram seus esfregaços realizados com material de coleta sorteado. A Tabela 2 demonstra a distribuição desta subamostra segundo o material de coleta, nos pacientes em que este foi sorteado randomicamente, e a capacidade que cada material apresentou na produção de resultados de Pap-a satisfatórios (normais e anormais) ou insatisfatórios. Os dados obtidos permitem a dedução de que, no material estudado, não houve diferença estatisticamente significante $(\mathrm{p}>0,05)$ na obtenção de resultados de leitura satisfatórios entre os três materiais de coleta utilizados.

\section{Discussão}

Muito embora referências na literatura apontem o swab de poliéster como material indicado para a realização da captura de células anais, pela propriedade que tem de liberá-las para a lâmina, por ocasião do esfregaço, com maior eficácia do que o swab de algodão hidrófilo, ${ }^{10,13}$ o presente estudo demonstra que, na amostra analisada, não houve diferença na qualidade do esfregaço realizado entre coletas feitas com um ou outro material. Tal achado reveste-se de importância em locais em que o custo da realização do screening em massa contra o câncer anal seja fator determinante para o sucesso de programas de prevenção, uma vez que, diferentemente do câncer cervical, o câncer anal é um câncer raro na população geral e sua prevenção em massa tem sido justificada, mediante critérios econômicos (relação custo-benefício), apenas em populações de risco. ${ }^{14}$

Em Manaus, o preço de balcão de um cotonete de algodão era de R\$ 0,02 em fevereiro de 2003, por ocasião da aquisição de material para a consecução da SPCA. À época, o preço de um swab de poliéster era de $\mathrm{R} \$ 0,18$. Caso os resultados obtidos por este estudo consigam ser corroborados por outros subseqüentes, e confirmem a eficácia do algodão na coleta de material anal para esfregaços citológicos com obtenção de leituras satisfatórias ao Pap-a, pode-se imaginar ser possível uma ampla difusão do método em nosso meio, considerando-se o custo baixo do material em relação a outros normalmente utilizados em exames citológicos (poliéster, espátulas de madeira, escovas citológicas, etc.).

Por serem estes os primeiros passos dos integrantes do Grupo de Pesquisa Escrutínio do Papaa, registrado no CNPQ, no Diretório de Grupos de Pesquisa no Brasil, na utilização do Pap-a como método auxiliar no diagnóstico precoce de alterações celulares que possam dar indícios da presença de degeneração maligna no canal anal, uma curva de aprendizado vem sendo observada, em todos os estágios da realização do trabalho, que tem determinado vários ajustes na metodologia utilizada. Assim ocorreu, por exemplo, com a realização dos esfregaços citológicos: os efetuados durante o grupo piloto demonstraram que o cotonete de algodão necessitava ser rolado sobre a lâmina em várias faixas 
de rolagem coalescentes (Figura 1), e não simplesmente esfregado, para produzir índices aceitáveis de satisfação de leitura citológica.

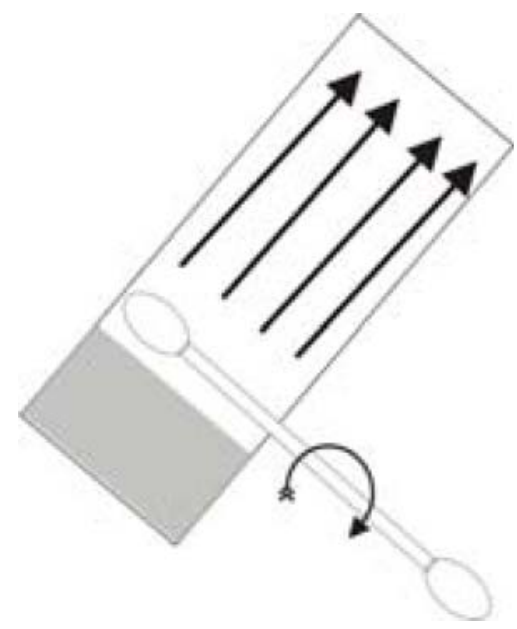

FIGURA 1 - O esfregaço foi produzido rolando-se o cotonete em torno de seu eixo sobre a parte transparente da lâmina, em faixas horizontais coalescentes, de forma a preencher toda a superfície de leitura da lâmina.

Os critérios para definir se um esfregaço citológico é ou não satisfatório, e, se satisfatório, se é ou não normal, são baseados em definições estabelecidas pelo consenso de Bethesda. ${ }^{21}$ Apesar de rigidamente estabelecidas, as regras acabam, em última análise, sofrendo a influência de uma série de fatores oriundos da intervenção humana no processo diagnóstico (qualidade da coleta, qualidade do esfregaço, condições de transporte da lâmina, etc.). Dentre estes fatores, talvez um dos mais determinantes seja a experiência do citopatologista em reconhecer a presença de alterações celulares sugestivas de lesões teciduais malignas ou pré-malignas e distingui-las de alterações benignas. Já foi descrita a falta de acurácia na leitura de lâminas em exames histopatológicos feitos para o diagnóstico do câncer anal pelo mesmo patologista, quando re-examinava a mesma lâmina meses mais tarde, ou por dois patologistas que examinam a mesma lâmina em centros diferentes. ${ }^{22}$ Se assim é para exames histopatológicos, não há porque ser diferente para citopatológicos, denotando que, afinal, todo laudo citológico encerra uma certa dose de subjetividade e, com esta, uma certa medida de falibilidade. Para citologias anais, os resultados descritos na literatura são ainda mais críticos do que para as cervicais. Em citologias anais realizadas em HAR HIV+ e HAR HIV- os índices de sensibilidade e especificidade do Pap-a publicados não são altos. ${ }^{23}$ Índices baixos que podem ser mais baixos ainda em indivíduois normais, nãopertencentes a grupos de risco.

Diante destes resultados, e de outros semelhantes publicados na literatura, ${ }^{14,15,23}$ o exato papel representado pelo Pap-a no diagnóstico precoce de lesões precursoras do câncer anal ainda continua sob intensa experimentação. Os dados até o momento obtidos apontam para o entendimento de que enquanto não se encontrar uma maneira mais prática, menos falível, mas economicamente viável de realizar a prevenção do câncer anal, o Pap-a continuará sendo utilizado para este desiderato.

Com base nesta assertiva, diminuir os custos de realização do exame, sem, no entanto, interferir em sua eficácia, pode ser fator preponderante para que se vençam barreiras naturais à disseminação deste método diagnóstico em países, como o Brasil, em que a priorização de campanhas de combate ao câncer tenha que, em última análise, ser calcada principalmente em fatores econômicos. Sendo, então, realmente, o algodão hidrófilo tão eficaz quanto outros materiais bem mais caros na capacidade de produzir leituras satisfatórias em esfregaços de secreções anais, como parecem apontar os resultados obtidos pelo presente estudo, uma oportunidade pode estar sendo encontrada para que o Pap-a seja mais amplamente adotado de forma rotineira na prevenção do câncer anal em populações de risco em nosso país.

\section{Conclusão}

A coleta de esfregaços anais com cotonetes de algodão apresentou eficácia estatisticamente análoga, no tocante à capacidade de produção de leituras satisfatórias do Pap-a, em relação às que foram obtidas com o emprego da escova citológica ou do swab de poliéster.

\section{Referências}

1. Carter PS. Anal cancer: Current perspectives. Dig Dis. 1993;11(4-5):239-51.

2. Daling JR, Weiss NS, Hislop TG eal. Sexual practices, sexually transmitted diseases, and the incidence of anal cancer. N Engl J Med. 1988;318(15):990-2.

3. Melbye M, Sprogel P. Aetiological parallel between anal cancer and cervical cancer. Lancet. 1991;338(8768):657-9.

4. Prieto R, Vazquez M. Anal epidermoid carcinoma: a rare incidence or a rare diagnosis?. Rev Esp Enferm Dig. 1997;89(2):128-32. 
5. Holly EA, Ralston ML, Darragh TM, Greenblatt RM, Jay N, Palefsky JM. Prevalence and risk factors for anal squamous intraepithelial lesions in women. J Natl Cancer Inst. 2001;93(11):843-9.

6. Frisch M, Glimelius B, Wohlfahrt J, Adami HO, Melbye M. Tobacco smoking as a risk factor in anal carcinoma: an antiestrogenic mechanism? J Natl Cancer Inst. 1999;91(8):708-15.

7. Daling JR, Weiss NS, Klopfenstein LL, Cochran LE, Chow WH, Daifuku R. Correlates of homosexual behavior and the incidence of anal cancer. J Am Med Assoc. 1982;247(14):1988-90.

8. Piketty C, Darragh TM, Da Costa M, Bruneval P, Heard I, Kazatchkine MD, Palefsky JM. High prevalence of anal human papillomavirus infection and anal cancer precursors among HIV-infected persons in the absence of anal intercourse. Ann Intern Med. 2003;138(6):453-9.

9. Moore HG, Guillem JG. Anal neoplasms. Surg Clin North Am. 2002;82(6):1233-51.

10. Martins CR. HPV-induced anal dysplasia: What do we know and what can we do about it? Hopkins HIV Rep. 2001;13(3):3-5.

11. Scholefield JH, McIntyre P, Palmer JG, Coates PJ, Shepherd NA, Northover JM. DNA hybridisation of routinely processed tissue for detecting HPV DNA in anal squamous cell carcinomas over 40 years. J Clin Pathol. 1990;43(2):133-6.

12. Fenger $C$. The anal transitional zone: location and extent. Acta Pathol Microbiol Scand. 1979;87A(5):379-86.

13. Daskalakis D. The anal pap: a guide for primary care providers. Available from URL: http://www.hivcouncil.org

14. Goldie SJ, Kuntz KM, Weinstein MC, Freedberg KA, Palefsky JM. Cost-effectiveness of screening for anal squamous intraepithelial lesions and anal cancer in human immunodeficiency virus-negative homosexual and bisexual men. Am J Med. 2000;108(8):634-41.

15. Palefsky JM, Holly EA, Hogeboom CJ, Berry JM, Jay N, Darragh TM. Anal cytology as a screening tool for anal squamous intraepithelial lesions. J Acquir Immune Defic Syndr Hum Retrovirol. 1997;14(5):415-22.
16. Hadjimichael O, Janerich D, Lowell DM, Meigs JW, Merino MJ, Schwartz PE. Histologic and clinical characteristics associated with rapidly progressive invasive cervical cancer: a preliminary report from the Yale Cancer Control Research Unit. Yale J Biol Med. 2000;62(4):345-50.

17. Darragh TM, Jay N, Tupkelewicz BA, Hogeboom CJ, Holly EA, Palefsky JM. Comparison of conventional 20. Agresti A. An introduction to categorical data analysis. New York: Wiley; 1996.

21. Smith JH. Bethesda 2001. Cytopathology. 2002;13(1):4-10.

22. Fenger C, Frisch M, Jass JJ, Williams GT, Hilden J. Anal cancer subtype reproducibility study. Virchows Arch. 2000;436(3):229-33.

23. de Ruiter A, Carter P, Katz DR, Kocjan G, Whatrup C, Northover J, Mindel A. A Comparison between cytology and histology to detect anal intraepithelial neoplasia. Genitourin Med. 1994;70(1):22-5.

\section{Agradecimentos}

O presente trabalho não teria sido realizado sem o inestimável apoio dos seguintes colaboradores: Prof. Dr. Luiz de Lima Ferreira (UFAM); Prof. Dr. Edmilson de Araujo Silva (UFAM); Dra . Elisangela Pinheiro Santana (UFAM); Prof $^{a}$. Dr ${ }^{\mathrm{a}}$. Ione Brum (UFAM); Prof. Dr. Jeconias Santana (UFAM); Dr. Pedro Elias de Souza (UFAM); Dr. Raul Rodrigues da Costa Neto (HAMN); Dra . Rosieny Batalha (IMT-AM); Aux. Adm. Juliana Barbosa Portela (HUGV UFAM); Acad. Med. Lívia Lima de Lima (UFAM); Acad. Med. Ruth Maria da Rocha Leal (UFAM); Acad. Med. Márcio Duarte Siosaki (UFAM); Acad. Med. Paulo Sérgio de Araújo Brasil Júnior (UFAM); Téc. Patol. Maria de Fátima Barbosa (HUGV-UFAM); Aux.Enf. Olenilda Lopes Goma - (HUGVUFAM); Aux.Enf. Paloma Cruz do Nascimento - (HUGVUFAM); Enf. Francisca do Perpétuo Socorro Marques (HUGV-UFAM); Aux.Enf. Selma Maria da Silva Dantas (HUGV-UFAM).
Correspondência:

Ivan Tramujas da Costa e Silva

Av. Efigênio Sales, 2055/149

69060-020 Manaus - AM

Fax:(92) 232-3411

tramujas@internext.com.br
Conflito de interesse: nenhum Fonte de financiamento: nenhuma

Recebimento: 06/09/2004

Revisão: 27/10/2004

Aprovação: 05/12/2004

\section{Como citar este artigo:}

Costa e Silva IT, Gimenez FS, Guimarães RAG, Camelo RT, Melo MND, Barros FS, Daumas A, Cabral CRB, Guimarães EL. Citologia anal como método de rastreamento para a detecção precoce do câncer anal: esfregaços com algodão hidrófilo são mesmo insatisfatórios? Acta Cir Bras. [serial online] 2005 Jan-Fev;20(1). Disponível em URL: $\underline{\text { htp://www.scielo.br/acb }}$ 